\title{
Influência da variação do nível hidrométrico na comunidade fitoplanctônica do Rio Paranapanema e de uma lagoa marginal na zona de desembocadura na Represa de Jurumirim (SP)
}

\author{
Danielli Cristina Granado ${ }^{1,4}$, Raoul Henry ${ }^{2}$ e Andréa Tucci ${ }^{3}$
}

Recebido: 03.07.2008; aceito: 20.02.2009

\begin{abstract}
Influence of hydrometric level variation on the phytoplanktonic community of the Paranapanema River and a marginal lake in its mouth zone into the Jurumirim Reservoir, São Paulo). The aim of this study was to show the effects of hydrometric level variation on phytoplankton structure of the Paranapanema River and a marginal lake in its mouth zone into Jurumirim Reservoir (SP). The samplings were collected in two stations in each environment from July 2004 to July 2005. The highest species richness and diversity of phytoplankton species were found in dry season, while them highest density and biovolume were recorded during the high water period The specie Cryptomonas brasiliensis Castro, C. Bicudo \& D. Bicudo (R-strategist) was constant along whole the study, being dominant, mainly, in the end of the drought and in the inundation, when the events of disturbances were more frequent. Diatoms predominated in biovolume in relation to other algae, mainly, for Aulacoseira granulata (Ehrenberg) Simonsem and their varieties. The great water volume stored in Jurumirim Reservoir acts as a "plug system" and the flood pulses of the main tributary are relatively weak. Thus, the stable water level is not a disturbance event that results in high increase of diversity in the studied environments, after the inundation. Key words: phytoplankton, hydrologic pulse, temporal variation
\end{abstract}

RESUMO - (Influência da variação do nível hidrométrico na comunidade fitoplanctônica do Rio Paranapanema e de uma Lagoa Marginal na zona de desembocadura na Represa de Jurumirim, São Paulo). Este estudo visou analisar os efeitos da variação do nível hidrométrico na estrutura do fitoplâncton do Rio Paranapanema e de uma lagoa marginal na zona de desembocadura no Reservatório de Jurumirim (SP). As amostragens foram realizadas em duas estações em cada ambiente de julho/2004 a julho/2005. Os maiores valores de riqueza e diversidade foram encontrados na estiagem, enquanto que as maiores densidade e biovolume foram registradas na cheia. A espécie Cryptomonas brasiliensis Castro, C. Bicudo \& D. Bicudo ( $\mathrm{R}$ - estrategista) foi constante ao longo de todo o estudo, sendo dominante, principalmente, no final da estiagem e na enchente, quando os eventos de distúrbios foram mais freqüentes. As diatomáceas foram predominantes quanto à biomassa, representadas, principalmente, por Aulacoseira granulata (Ehrenberg) Simonsem e suas variedades. Conclui-se que, o volume de água acumulada no reservatório à jusante não permite que o pulso hidrológico ocasione um distúrbio que resulte em elevado aumento da diversidade nos ambientes estudados, após a enchente.

Palavras-chave: fitoplâncton, pulso hidrológico, variação temporal

\section{Introdução}

A existência de áreas inundáveis no entorno dos cursos de água é considerada como um fator natural e regular, comumente observado na maioria dos cursos de água de médio e grande porte. Em períodos de enchentes, os rios invadem as depressões laterais e quando as águas baixam, após o pulso de inundação formam-se verdadeiros lagos, interligados ou não com o canal principal (Junk 1980). As lagoas marginais são consideradas fundamentais para a manutenção da biodiversidade de planícies de inundação, pois favorecem o desenvolvimento de populações planctônicas distintas das encontradas no rio e de macrófitas aquáticas nas regiões litorâneas, propiciando grande variedade de nichos para os organismos aquáticos. A variação hidrológica anual do rio é o mais importante fator regulador do metabolismo dos ecossistemas rio - planície de inundação (Junk 1997).

1. Escola de Engenharia de São Carlos, Centro de Recursos Hídricos e Ecologia Aplicada, Caixa Postal 292, 13560-970 São Carlos, SP, Brasil

2. Universidade Estadual Paulista, Instituto de Biociências, Departamento de Zoologia, Caixa Postal 510, 18618-000 Botucatu, SP, Brasil

3. Instituto de Botânica, Caixa Postal 3005, 01061-970 São Paulo, SP, Brasil

4. Autor para correspondência: daniellicg@yahoo.com.br 
As intensas mudanças na dinâmica dos ambientes de planície de inundação ocasionadas pela variação hidrométrica afetam diretamente as comunidades das lagoas marginais, em especial, o fitoplâncton, cuja variação sazonal tem sido fortemente relacionada ao pulso de inundação (Garcia-de-Emiliani 1993, 1997, Huszar \& Reynolds 1997, Putz \& Junk 1997, Ibanez 1998, Train \& Rodrigues 1998, Melo \& Huszar 2000, Oliveira \& Calheiros 2000, Domitrovic 2003, Taniguchi et al. 2005, Nabout et al. 2006).

Vários estudos em lagoas marginais registraram no período de cheia, reduções nos valores de densidade e biomassa fitoplanctônica, devido ao efeito de diluição, como os observados na planície de inundação do Rio Paraná (Garcia-de-Emiliani 1997, Domitrovic 2003), no Lago Batata, na Amazônia (Huszar \& Reynolds 1997, Melo \& Huszar 2000), na Lagoa Sá Mariana, no pantanal de Mato Grosso (LouverdeOliveira \& Huszar 2007), na área alagável do rio Daugava (Letônia) (Padiere et al. 2007). Embora, elevadas biomassas já tenham sido observadas nas fases de enchente e cheia, relacionadas ao aporte de matéria orgânica da planície inundada, como observado na Lagoa do Diogo, lateral ao rio Mogi Guaçu (Peres \& Senna 2000, Taniguchi et al. 2005).

Espécies de algas $\mathrm{C}$ - estrategistas (especialmente clorofíceas) são freqüentemente registradas no início da enchente quando os distúrbios hidráulicos são menos freqüentes. Em seguida, com o aumento dos eventos de perturbação, há predomínio de $\mathrm{R}$ - estrategistas (criptofíceas), que mais tarde são substituídas por S - estrategistas (euglenofíceas e dinoflagelados) após a redução da frequiência dos distúrbios (Garcia-de-Emiliani 1997). Outras vezes, são observadas ocorrências de comunidades bastante diversificadas, composta por pequenas clorofíceas (clorococales), diatomáceas e desmídias, como consequiência do lento enchimento das lagoas laterais (Huszar \& Reynolds 1997). Espécies de diatomáceas como Aulacoseira granulata (Ehrenberg) Simonsen e suas variedades, também têm presença constante em lagoas marginais, com elevada representatividade em biomassa nos períodos de enchente e cheia (Nabout et al. 2006, Louverde-Oliveira \& Huszar 2007).

O objetivo do presente estudo foi analisar os efeitos da variação do nível hidrométrico, caracterizada pela flutuação natural e pelo manejo da represa, sobre a estrutura da comunidade fitoplanctônica (riqueza, diversidade, densidade, biovolume e espécies descritoras da comunidade) do Rio Paranapanema e de uma lagoa marginal (Lagoa do Camargo) na zona de desembocadura no Reservatório de Jurumirim (SP).

\section{Material e métodos}

O Rio Paranapanema é um dos principais afluentes do Rio Paraná no Estado de São Paulo. Ao longo de seu percurso foi construído uma série de reservatórios em "cascata" com a finalidade de geração de energia elétrica. O primeiro deles é o Reservatório de Jurumirim, localizado na região sudeste do Estado de São Paulo, entre os paralelos $23^{\circ} 08^{\prime} \mathrm{S}$ e $23^{\circ} 35^{\prime} \mathrm{S}$ e os meridianos $48^{\circ} 30^{\prime} \mathrm{W}$ e $49^{\circ} 13^{\prime} \mathrm{W}$. Na zona de desembocadura do Rio Paranapanema no Reservatório de Jurumirim, encontram-se algumas lagoas marginais, entre elas a Lagoa do Camargo (figura 1), que possui área superficial de $224.465 \mathrm{~m}^{2}$, volume de $719.867 \mathrm{~m}^{3}$, profundidade máxima de $3,9 \mathrm{~m}$, sendo permanentemente conectada ao canal do Rio (Henry 2005).

As amostragens foram realizadas mensalmente, entre o período de julho de 2004 a julho de 2005. As amostras foram coletadas com garrafa de van Dorn na superfície, em duas estações no Rio Paranapanema e em duas estações na Lagoa do Camargo, uma localizada junto à conexão com o Rio e outra no centro da lagoa (figura 1).

As variáveis físicas e químicas da água analisadas foram: temperatura da água (termistor Toho Dentan ET-3); condutividade elétrica (condutivímetro Hatch com valores corrigidos para $25^{\circ} \mathrm{C}$, de acordo Golterman et al. 1978); velocidade da correnteza (correntômetro ELE); transparência da água (disco de Secchi); material em suspensão (Teixeira \& Kutner 1962); alcalinidade (Mackeret et al. 1978); pH (pHmetro, Micronal B380); oxigênio dissolvido (Golterman et al. 1978); nitrogênio total, nitrito, nitrato (Mackereth et al. 1978); amônia (Koroleff 1976); fósforo total, fosfato total dissolvido, fosfato inorgânico (Strickland \& Parsons 1960) e silicato reativo (Golterman et al. 1978).

Os dados de precipitação foram obtidos na estação pluviométrica E-5-017 do Departamento de Água de Energia Elétrica (DAAE), localizada no município de Angatuba, (distante $30 \mathrm{Km}$ do local de estudo). Os valores de nível hidrométrico foram fornecidos pelo setor de operação da barragem da represa de Jurumirim da Companhia Duke Energy. Segundo Pompêo et al. (1999), há correspondência entre os padrões de variação do nível de água na barragem e na zona desembocadura do rio Paranapanema na represa de Jurumirim.

O estado trófico dos ambientes foi calculado segundo o índice de Carlson (1977) modificado, ponderado pela equação proposta por Toledo et al. (1983). 
As amostras para as análises quantitativas da comunidade fitoplanctônica foram fixadas com lugol acético e a contagem foi realizada de acordo com Utermöhl (1958) em microscópio invertido Leica, em aumento de 400 vezes. Foram considerados como um indivíduo organismos unicelulares, coloniais e filamentosos. A contagem de organismos foi realizada em transectos horizontais até a obtenção de 100 indivíduos da espécie mais freqüiente e/ou pela curva de estabilização do número de espécies. Foram calculados a frequiência de ocorrência, a densidade (APHA 1995), a riqueza, a diversidade (Shannon \& Weaver 1963) e o biovolume das espécies (Wetzel \& Likens 1991, Hillebrand et al. 1999).
Foram consideradas espécies descritoras da comunidade, aquelas cuja densidade e biovolume superior a $1 \%$ do valor total e que juntas representaram $80 \%$ da comunidade (Sommer et al. 1993).

Para mostrar a distribuição temporal dos dados abióticos e suas relações com as espécies descritoras foram aplicadas uma Análise de Componentes Principais (ACP) e uma Análise de Correspondência Canônica (ACC). Os dados bióticos e abióticos foram transformados através do programa FITOPAC (Shepherd 1996) e as análises multivariadas foram feitas pelo programa PCORD versão 3.1 para Windows (McCune \& Meford 1997).

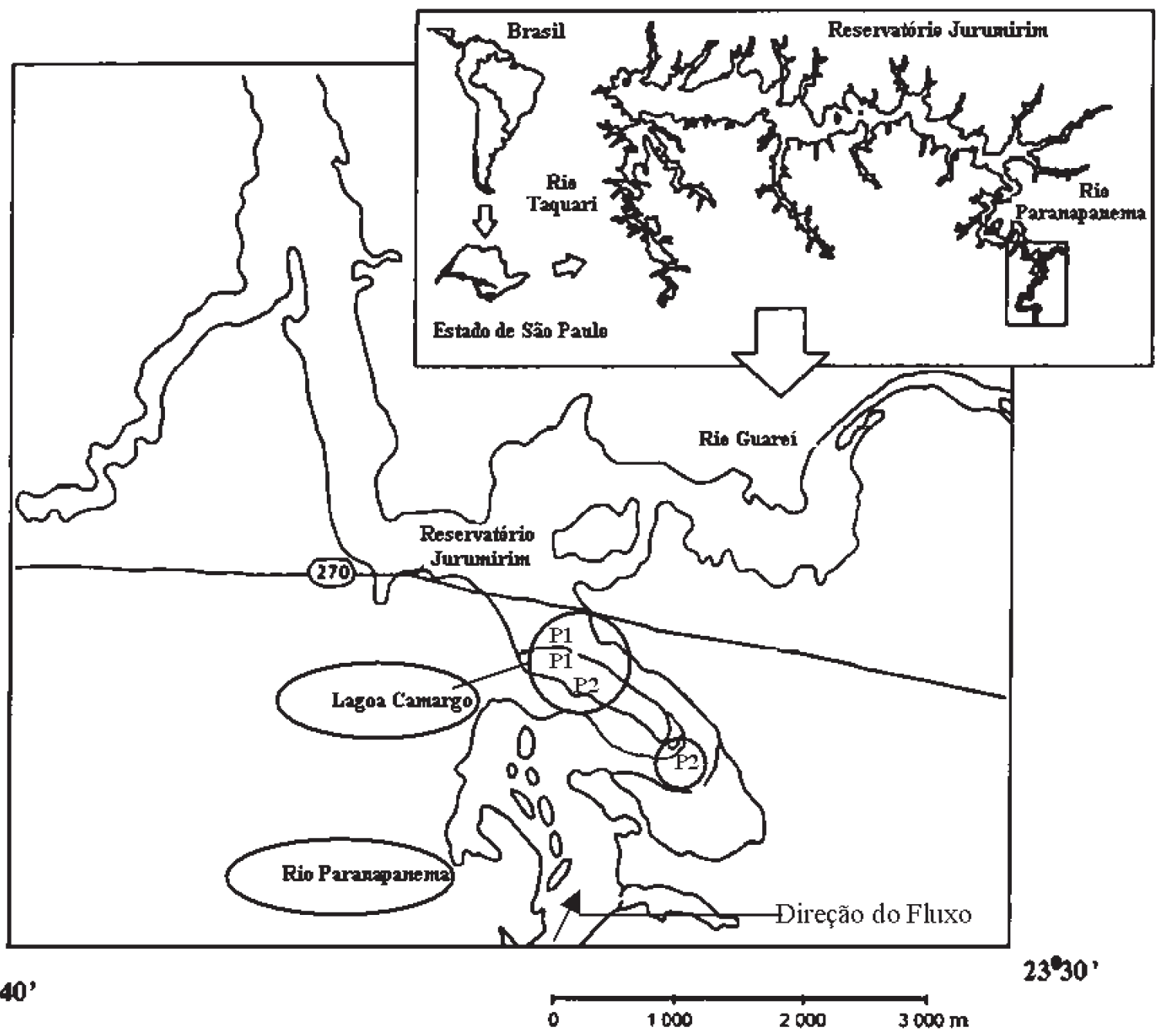

Figura 1. Região de desembocadura do Rio Paranapanema no Reservatório de Jurumirim, onde localiza-se a Lagoa do Camargo, com as respectivas estações (P1 e P2) de coleta.

Figure 1. The mouth zone of the Paranapanema River into the Jurumirim Reservoir, where the Camargo Lake and the respective stations (P1 and P2) are located. 


\section{Resultados}

Durante o ano de estudo, o maior valor de precipitação mensal ocorreu em janeiro de 2005 (244 $\mathrm{mm})$. Valores superiores a $100 \mathrm{~mm}$ foram observados apenas em outubro (114 mm) e dezembro de 2004 (120 $\mathrm{mm})$. Em agosto e setembro foi verificado um período de estiagem (figura $2 \mathrm{a}$ ).

A Lagoa do Camargo manteve-se permanentemente conectada ao curso de água, visto que o nível de fronteira entre conexão/isolamento da lagoa com o rio é igual a 563,6 m (Henry 2005). Os maiores níveis hidrométricos foram registrados em junho e julho de 2004 (566,82 m). Os valores reduziram-se até 564,49 $\mathrm{m}$, em novembro de 2004 e voltaram a aumentar nos meses subseqüentes, atingindo $566,43 \mathrm{~m}$ em fevereiro de 2005, para diminuir até 565,63 em julho de 2005. Em função dessa variação, cinco diferentes períodos foram identificados: vazante (julho, agosto e setembro de 2004), estiagem (outubro, novembro e dezembro de 2004), enchente (janeiro e fevereiro de 2005), cheia (março e abril de 2005) e vazante (maio, junho e julho de 2005) (figura 2b). A profundidade da lagoa do Camargo foi menor na fase de estiagem e maior no início da vazante de 2004 (tabela 1).

A velocidade da corrente no Rio Paranapanema seguiu um padrão evidente e relacionado à variação da precipitação. Os valores mais baixos foram obtidos no final da vazante de 2004 (cerca de $0,15 \mathrm{~m} \mathrm{~s}^{-1}$ nas duas estações). A partir do período de estiagem, a velocidade aumentou até atingir os valores mais altos em no final da enchente (cerca de $0,85 \mathrm{~m} \mathrm{~s}^{-1}$ ); diminuiu para cerca de $0,3 \mathrm{~m} \mathrm{~s}^{-1}$ na cheia com pouca alteração até o final do estudo (figura 2c).

Os valores de temperatura na superfície da água foram menores no período de vazante de 2004 e mais elevados durante a cheia, final do verão. As variáveis, condutividade elétrica da água, alcalinidade e $\mathrm{pH}$ apresentaram um padrão de variação similar nos dois ambientes. Os valores das duas primeiras foram maiores no período de estiagem e menores no período final da enchente, enquanto que os valores de $\mathrm{pH}$ foram mais baixos na vazante e mais elevados na fase de estiagem (tabela 1).

Baixa transparência da água foi registrada no período de estiagem, em consequiência das elevadas concentrações de material em suspensão nesta fase (tabela 1). Elevados valores de transparência foram obtidos na vazante, quando foram observadas as menores concentrações de material suspenso na água. A amplitude de variação dessa variável no Rio foi maior do que na Lagoa, que aumentou dois metros de profundidade do período seco ao final da enchente (tabela 1).

As concentrações de oxigênio dissolvido na água foram mais elevadas no Rio Paranapanema, sendo que os maiores valores foram encontrados na vazante (tabela 1$)$.

Tabela 1. Valores mínimos e máximos das variáveis físicas e químicas da água, no Rio Paranapanema e na Lagoa do Camargo entre julho de 2004 e julho de 2005 ( $\mathrm{n}=26$ ) (Abreviaturas Mín. e Max., correspondem a valores mínimo e máximo e as letras X e DP, a média e desvio padrão, respectivamente.

Table 1. Minimum and maximum values of water physical and chemical variables in the Paranapanema River and Camargo Lake from July 2004 to July $2005(\mathrm{n}=26)$ (The Min. and Max. abbreviations indicate minimum and maximum values, and letters X and DP, the mean and standard deviation, respectively).

\begin{tabular}{|c|c|c|c|c|}
\hline \multirow[b]{2}{*}{ Variáveis } & \multicolumn{2}{|c|}{ Rio Paranapanema } & \multicolumn{2}{|c|}{ Lagoa do Camargo } \\
\hline & Mín. - Máx. & $\mathrm{X}-\mathrm{DP}$ & Mín. - Máx. & $\mathrm{X}-\mathrm{DP}$ \\
\hline Temperatura $\left({ }^{\circ} \mathrm{C}\right)$ & $15,2-26$ & $20,5 \pm 3,6$ & $15,2-27,8$ & $22,2 \pm 4,2$ \\
\hline Condutividade elétrica $\left(\mu \mathrm{S} \mathrm{cm}^{-1}\right)$ & $44,1-86,7$ & $64 \pm 11$ & $49-71,4$ & $60 \pm 7$ \\
\hline $\mathrm{pH}$ & $6,4-7,1$ & $6,7 \pm 0,18$ & $6,3-7,1$ & $6,7 \pm 0,20$ \\
\hline Material em suspensão $\left(\mathrm{mg} \mathrm{L}^{-1}\right)$ & $4-66$ & $15 \pm 14$ & $4-17$ & $9 \pm 4$ \\
\hline Profundidade (m) & - & - & $1,7-3,7$ & $3,0 \pm 0,7$ \\
\hline Transparência (m) & $0,32-1,3$ & $0,82 \pm 0,3$ & $0,28-1,58$ & $0,83 \pm 0,4$ \\
\hline Alcalinidade (meq L ${ }^{-1}$ ) & $0,273-0,503$ & $0,412 \pm 0,06$ & $0,286-0,449$ & $0,386 \pm 0,05$ \\
\hline Oxigênio dissolvido $\left(\mathrm{mg} \mathrm{L}^{-1}\right)$ & $7,4-11,5$ & $9,2 \pm 1,3$ & $5,4-10,1$ & $8,0 \pm 1,2$ \\
\hline Nitrogênio total $\left(\mu \mathrm{g} \mathrm{L}^{-1}\right)$ & $115-667$ & $324 \pm 154$ & $75-526$ & $262 \pm 128$ \\
\hline Fósforo total $\left(\mu \mathrm{g} \mathrm{L}^{-1}\right)$ & $5-87$ & $22 \pm 21$ & $2-55$ & $23 \pm 14$ \\
\hline Amônia $\left(\mu \mathrm{g} \mathrm{L}^{-1}\right)$ & $6-70$ & $29 \pm 19$ & $4-52$ & $20 \pm 16$ \\
\hline Nitrato $\left(\mu \mathrm{g} \mathrm{L}^{-1}\right)$ & $55-338$ & $129 \pm 55$ & $0-208$ & $60 \pm 51$ \\
\hline Nitrito $\left(\mu \mathrm{g} \mathrm{L}^{-1}\right)$ & $8-42$ & $16 \pm 8$ & $5-22$ & $11 \pm 4$ \\
\hline Fosfato total dissolvido $\left(\mu \mathrm{g} \mathrm{L}^{-1}\right)$ & $3-49$ & $14 \pm 12$ & $0-39$ & $16 \pm 11$ \\
\hline Fosfato inorgânico $\left(\mu \mathrm{g} \mathrm{L}^{-1}\right)$ & $0-36$ & $9 \pm 9$ & $0-31$ & $10 \pm 8$ \\
\hline Silicato reativo $\left(\mathrm{mg} \mathrm{L}^{-1}\right)$ & $0,8-7,8$ & $5 \pm 2$ & $0,4-7,5$ & $5 \pm 2$ \\
\hline
\end{tabular}



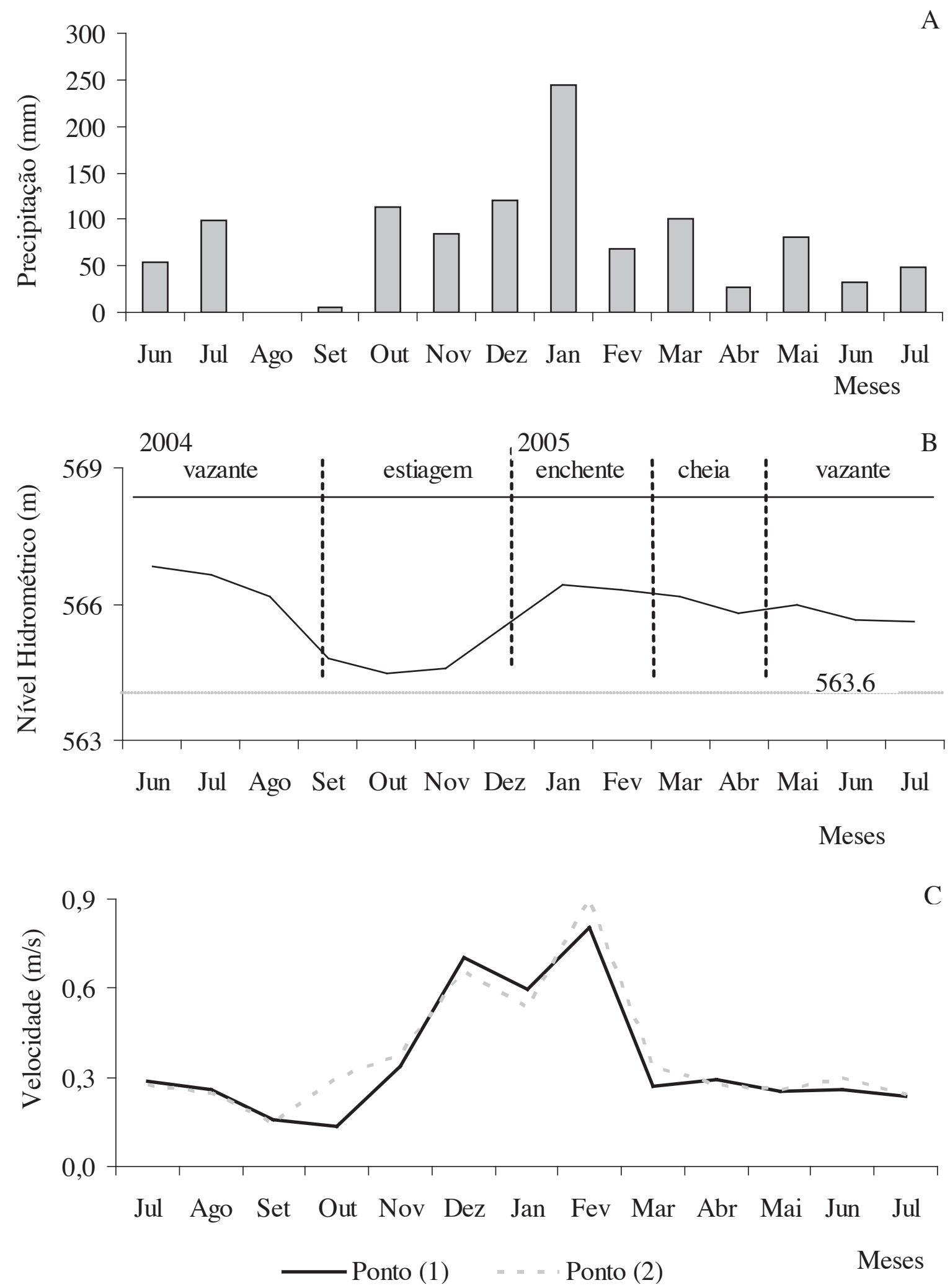

Figura 2. Precipitação mensal acumulada ( $\mathrm{mm}$ ) (a), variação mensal do nível hidrométrico (m) na zona da barragem de Jurumirim (b) e velocidade da correnteza $\left(\mathrm{m} \mathrm{s}^{-1}\right)$ no Rio Paranapanema (c), entre julho/04 e julho/05.

Figure 2. Accumulated monthly rainfall (mm) (a), hydrometric level monthly variation (m) in the Jurumirim (b), and the Paranapanema River current velocity ( $\mathrm{m} \mathrm{s}^{-1}$ ) (c) from July 2004 to July 2005. 
As maiores concentrações de nutrientes foram registradas na fase de estiagem nos dois ambientes, com exceção do amônio e do silicato no Rio, cujas concentrações foram mais elevadas na cheia; e do nitrogênio total, do amônio e do fosfato inorgânico na lagoa, que foram maiores na enchente. No período de vazante foram observadas as menores concentrações para os dois ambientes, exceto para as formas de fósforo, cujos valores foram mais baixos na cheia (tabela 1).

O índice do estado trófico revelou que, durante o período estudado, o Rio Paranapanema e a Lagoa do Camargo foram consideradas como ambientes eutróficos. No Rio, o maior valor médio por período ocorreu na enchente (66) e o menor, na vazante de 2004 (58). No ecossistema lêntico, valores médios mais elevados foram registrados na estiagem e na enchente (64), enquanto que o mais baixo foi observado na cheia (55).

A análise de componentes principais (ACP) avaliou as principais tendências nas escalas temporal e espacial. Aos dois primeiros eixos foram atribuídos $53,6 \%$ da variabilidade dos dados abióticos. Fósforo total e ortofosfato, transparência da água, material em suspensão e nitrogênio total foram mais importantes na ordenação do primeiro eixo, enquanto que, alcalinidade e condutividade mostraram maior correlação com o eixo 2 (tabela 2). A distribuição dos dados mostra um comportamento temporal similar entre as estações 1 e 2 de cada ambiente, em função da variação de nível hidrométrico. Nas fases de enchente e cheia foram observadas similaridades entre os dois ambientes, enquanto que na estiagem e vazante a diferença mostrou-se clara, com a maioria

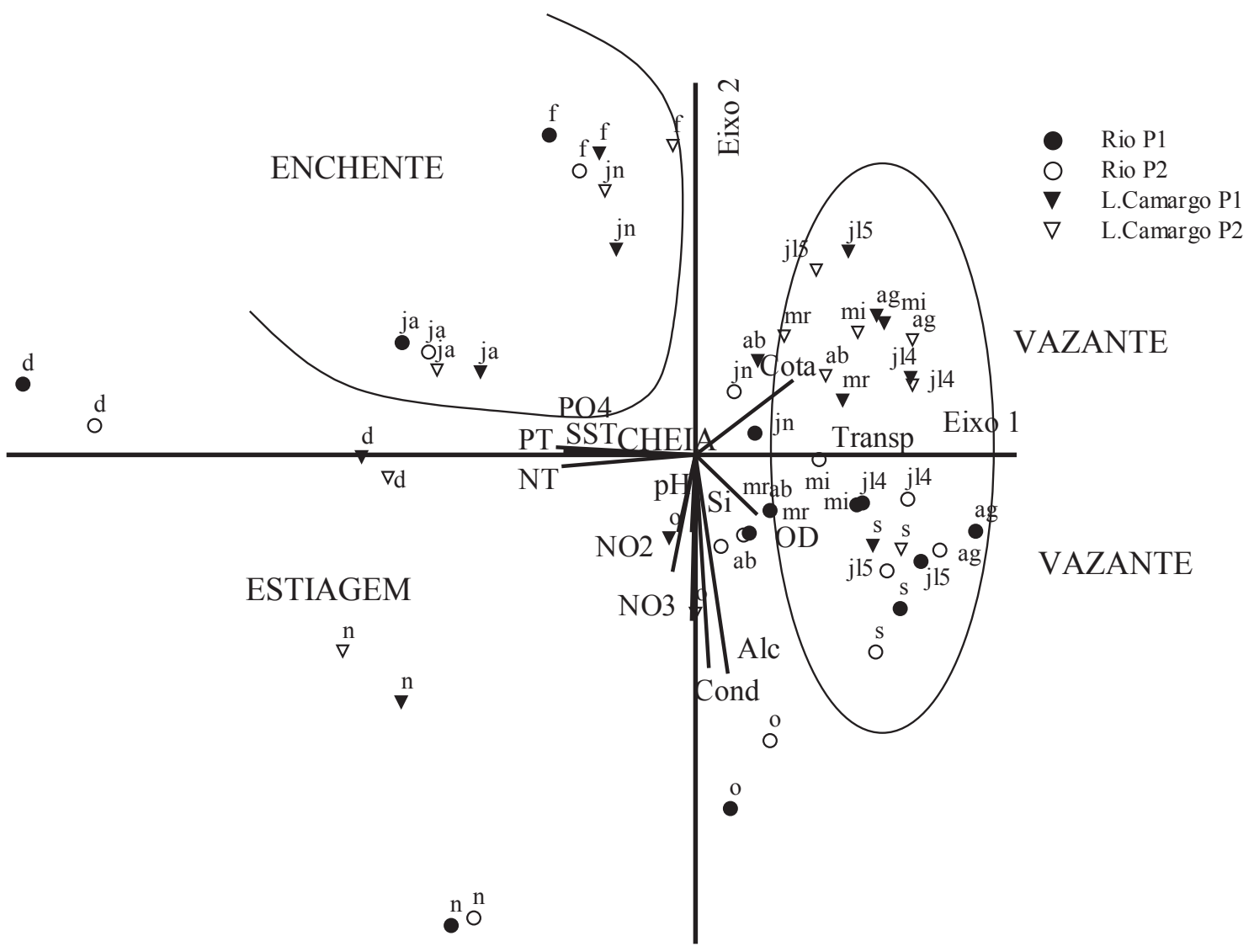

Figura 3. Ordenação pela ACP (eixos 1 e 2) dos meses e pontos amostrados, no período de julho de 2004 e julho de 2005 . As letras que acompanham as unidades amostrais são referentes as iniciais dos meses coletados (j1/4: julho de 2004, ag: agosto, s: setembro, o: outubro, n: novembro, d: dezembro, ja: janeiro, f: fevereiro, mr: março, ab: abril, mi: maio, jn: junho e j15: julho de 2005).

Figure 3. PCA ordination (axes 1 and 2) of sampling months and stations from July 2004 to July 2005. Letters together with sampling units refer to the sampling months (j1/4: July 2004, ag: August, s: September, o: October, n: November, d: December, ja: January, f: February, mr: March, ab: April, mi: May, jn: June and j15: July 2005). 
das unidades amostrais do Rio localizadas no lado negativo do eixo 1 e a maioria das unidades amostrais da Lagoa, do lado positivo do mesmo eixo.

Ao longo do período de estudo foram encontrados 154 táxons distribuídos entre Chlorophyceae (63 táxons), Bacillariophyceae (28), Cyanobacteria (23), Zygnemaphyceae e Euglenophyceae (12 táxons cada uma), Cryptophyceae (5), Chrysophyceae (4), Dinophyceae (2) e Xanthophyceae (1). A maior riqueza (135 táxons) foi registrada no Rio Paranapanema, que apresentou 49 táxons exclusivos (23 Chlorophyceae e 11 Bacillariophyceae). Na Lagoa do Camargo foram encontrados 106 táxons, sendo 20 exclusivos, (principalmente fitoflagelados). O único representante de Xanthophyceae, Ophiocytium sp. também foi encontrado somente na lagoa. Oitenta e seis táxons ( $56 \%$ do total) foram comuns aos dois ambientes.

No Rio Paranapanema duas espécies, Closteriopsis acicularis (Chlorophyceae) e Cryptomonas brasiliensis (Cryptophyceae), foram constantes, ou seja, presentes em mais de $90 \%$ das amostragens. Ainda no Rio, Aulacoseira granulata var. granulata, Chlorella vulgaris, Golenkinia radiata, Monoraphidium griffithii foram freqüentes. Já Discotella meneghiniana, Discotella stelligera e Monoraphidium contortum foram freqüentes nos dois ambientes.
A riqueza e a diversidade de espécies no Rio Paranapanema foram mais elevadas no período de estiagem, enquanto que valores mais baixos foram encontrados durante a fase de enchente e vazante de 2005 (figura 4a, b). Na Lagoa, maior número de táxons e diversidade foi obtido na vazante de 2004, enquanto que os menores valores foram registrados na enchente.

Elevadas densidades e biomassas fitoplanctônicas (biovolume) foram encontradas no período de cheia em ambos ambientes. No Rio, a densidade foi mais baixa na vazante de 2004 e, o biovolume no período de enchente. Na Lagoa do Camargo, menores valores de densidade e biomassa foram registrados na vazante de 2004 (figura 4c, d).

No Rio Paranapanema, Chlorophyceae contribuiu com mais de $78 \%$ da densidade total, especialmente, no período de cheia (figura 5a). As algas verdes foram representadas, principalmente, por Closteriopsis acicularis e por outras espécies de Chlorococcales, como Dictyosphaerium pulchellum, e Monoraphidium spp. As diatomáceas apresentaram a segunda maior contribuição, com mais de $30 \%$ da densidade total, no final da vazante de 2004 e início da estiagem. No final da estiagem, da enchente e da vazante de 2005, as Cryptophyceae contribuíram com $29 \%, 35 \%$ e $50 \%$ da densidade total, respectivamente, representadas quase que exclusivamente por Cryptomonas brasiliensis (figura 5a).

Tabela 2. Coeficiente de Correlação de Pearson entre as variáveis abióticas e os dois primeiros eixos de ordenação da ACP para o período compreendido entre julho de 2004 e julho de 2005.

Table 2. Pearson correlation coefficient between abiotic variables and the two first axes of PCA ordination for the period from July 2004 to July 2005.

\begin{tabular}{lccc}
\hline & & \multicolumn{2}{c}{ Componentes Principais } \\
\hline Alcalinidade & Abreviações & Eixo 1 & Eixo 2 \\
\cline { 3 - 4 } Condutividade Elétrica & Alc & 0,406 & $\mathbf{- 0 , 8 2 2}$ \\
Oxigênio Dissolvido & Cond & 0,249 & $\mathbf{- 0 , 8 1 3}$ \\
pH & $\mathrm{OD}$ & 0,547 & $-0,424$ \\
Material em Suspensão & $\mathrm{pH}$ & $-0,150$ & $-0,486$ \\
Temperatura & $\mathrm{SST}$ & $\mathbf{- 0 , 8 0 5}$ & 0,099 \\
Transparência da Água & Temp & $-0,380$ & $-0,032$ \\
Nitrogênio & Transp & $-0,032$ \\
Fósforo & $\mathrm{NT}$ & 0,825 & $-0,185$ \\
Silicato & $\mathrm{PT}$ & $-0,814$ & 0,021 \\
Nível Hidrométrico & $\mathrm{Si}$ & $\mathbf{- 0 , 8 8 4}$ & $-0,488$ \\
Ortofosfato & $\mathrm{Cota}$ & $-0,285$ & 0,480 \\
Amônio & $\mathrm{PO}_{4}$ & 0,692 & 0,156 \\
Nitrato & $\mathrm{NH}_{4}$ & $\mathbf{- 0 , 8 3 2}$ & $-0,130$ \\
Nitrito & $\mathrm{NO}_{3}$ & $-0,156$ & $\mathbf{- 0 , 7 1 4}$ \\
Total da Explicabilidade & $\mathrm{NO}_{2}$ & $-0,136$ & $-0,599$ \\
\hline
\end{tabular}



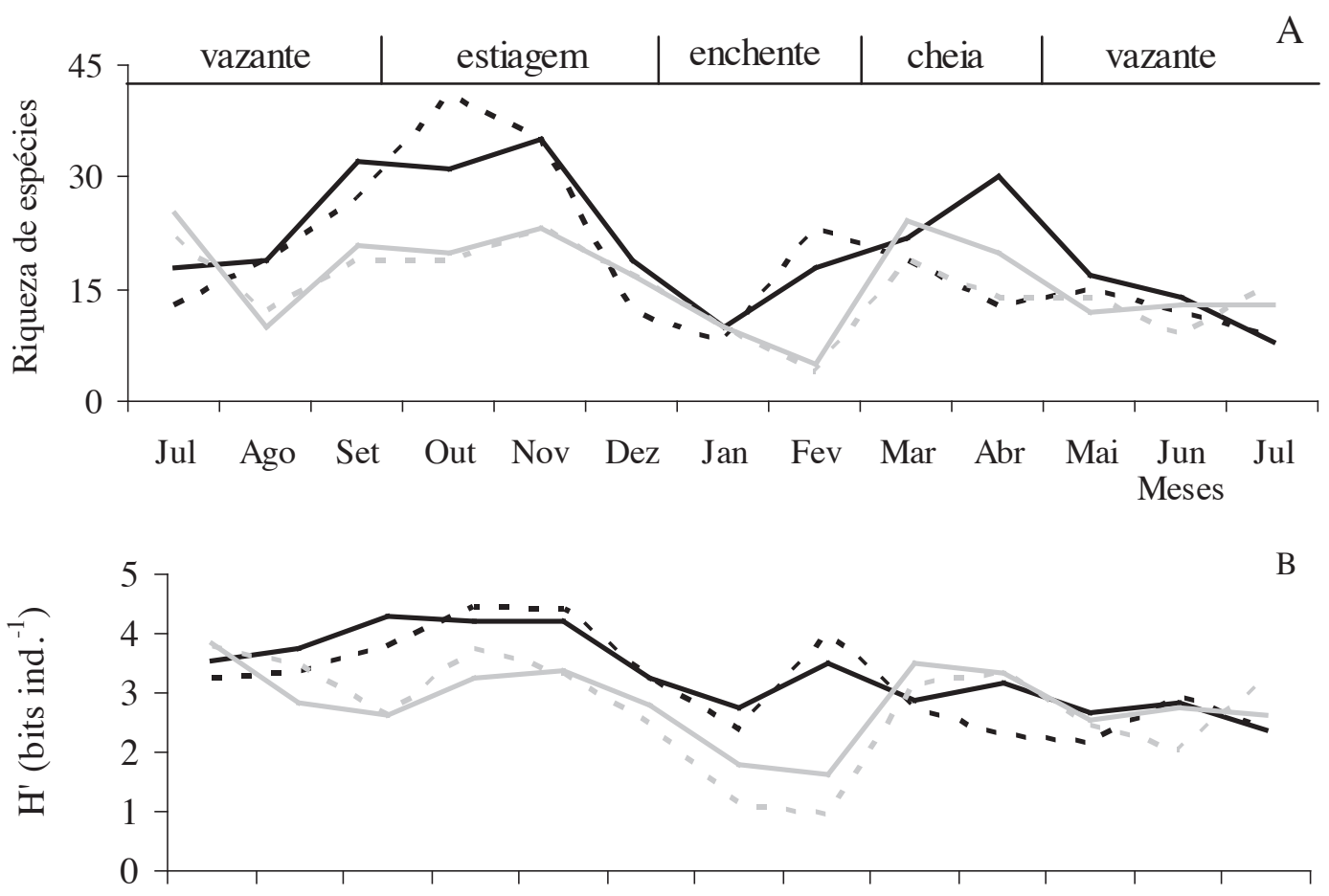

Jul Ago Set Out Nov Dez Jan Fev Mar Abr Mai Jun Jul Meses

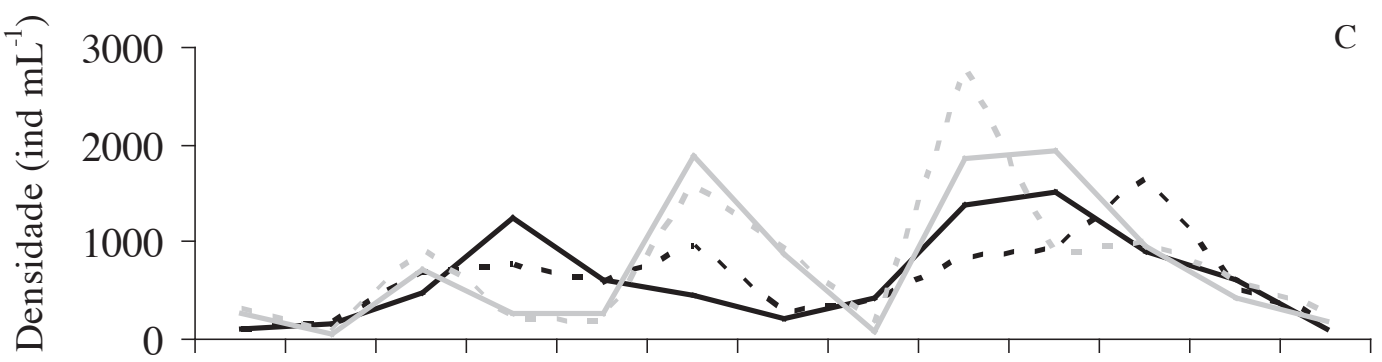

Jul Ago Set Out Nov Dez Jan Fev Mar Abr Mai Jun Jul Meses

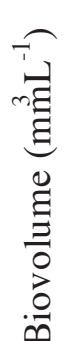

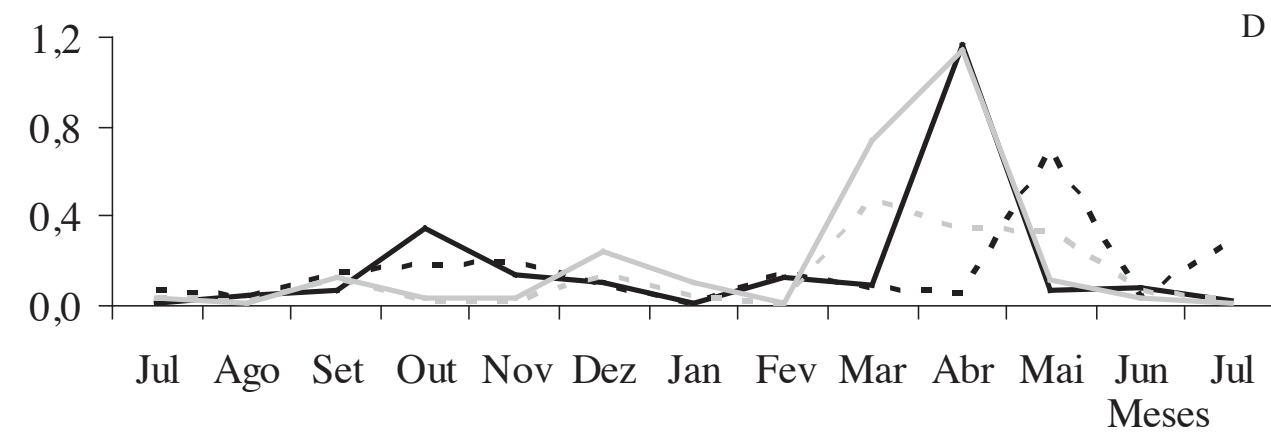

$\longrightarrow$ Rio P1 - - Rio P2 CamP1 = = CamP2

Figura 4. Variação da riqueza (número de táxons) (a), diversidade (bits ind.) (b), densidade (ind $\mathrm{mL}^{-1}$ ) (c) e biomassa fitoplanctônica (biovolume em $\mathrm{mm}^{3} \mathrm{~L}^{-1}$ ) (d) no Rio Paranapanema e na Lagoa do Camargo entre julho de 2004 e julho de 2005.

Figure 4. Phytoplankton richness (taxa number) (a), diversity (bits ind..$^{-1}$ ) (d) density (ind $\left.\mathrm{mL}^{-1}\right)(\mathrm{c})$, and biomass (biovolume in mm ${ }^{3} \mathrm{~L}^{-1}$ ) (d) variations in the Paranapanema River and Camargo Lake from July 2004 to July 2005. 
Na Lagoa do Camargo, padrão similar de contribuição das classes para a densidade foi observado nos dois locais de coleta. Com exceção do final da vazante e do final da cheia, as Cryptophyceae, contribuíram com mais de $50 \%$ da densidade total de meados da estiagem ao início da cheia e durante a vazante de 2005, sendo Cryptomonas brasiliensis a espécie predominante. No final da vazante de 2004, as Bacillariophyceae contribuíram com $71 \%$ da densidade total; representadas, principalmente, por Discotella meneghiniana e D. stelligera (figura 5a).
Quanto ao biovolume, as diatomáceas apresentaram maiores valores no Rio Paranapanema, contribuindo com mais de $50 \%$ do biovolume total, no final da vazante e durante a estiagem (figura 6a). A classe foi representada, quase que inteiramente pela ordem Centrales, com destaque para Aulacoseira granulata. Em alguns meses da fase de enchente, da cheia e da vazante, Chlorophyceae predominou com mais de $40 \%$ da biomassa total, sendo Eudorina elegans e Botryococcus braunii as espécies mais importantes (figura 6a).

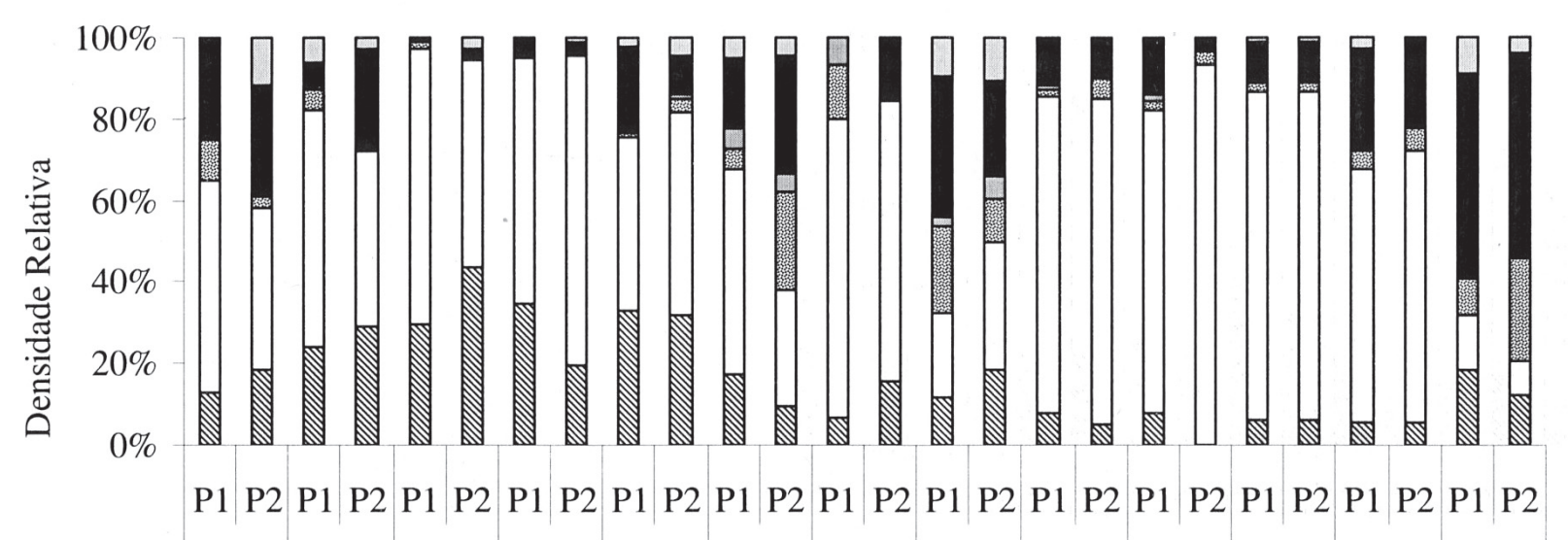

\begin{tabular}{l|l|l|l|l|l|l|l|l|l|r|r|r|} 
Jul & Ago & Set & Out & Nov & Dez & Jan & Fev & Mar & Abr & Mai & Jun \\
Meses
\end{tabular}

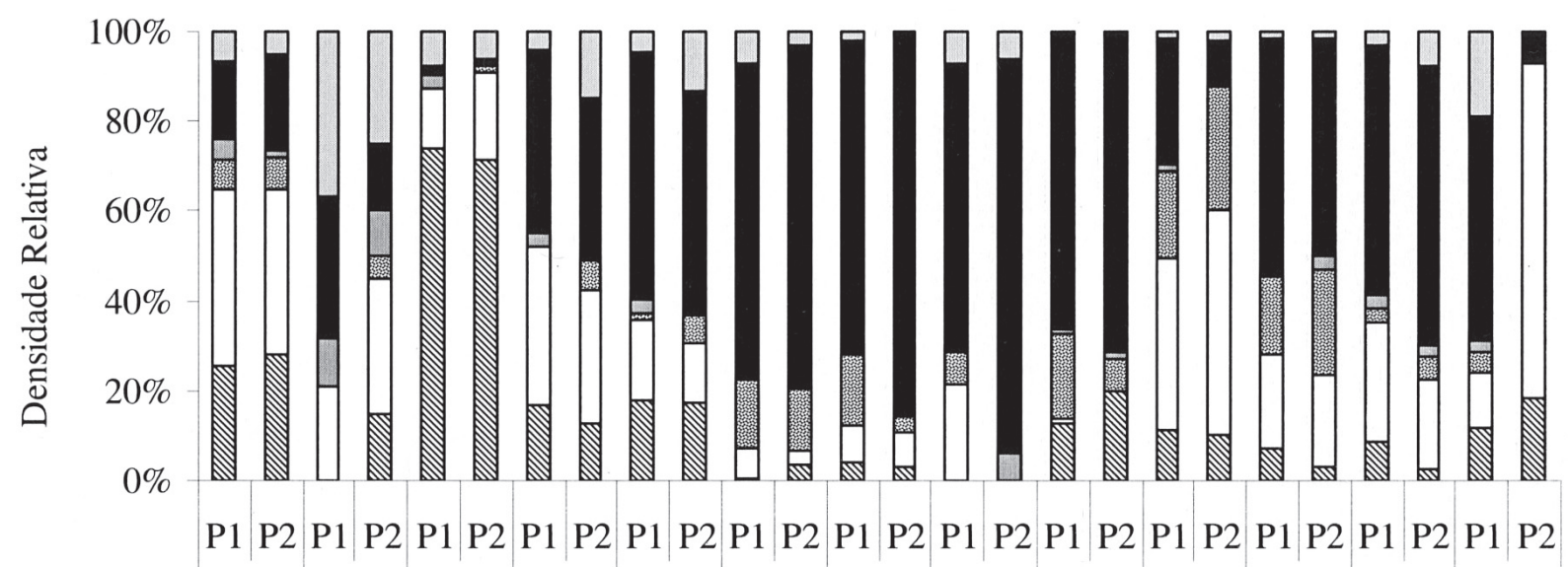

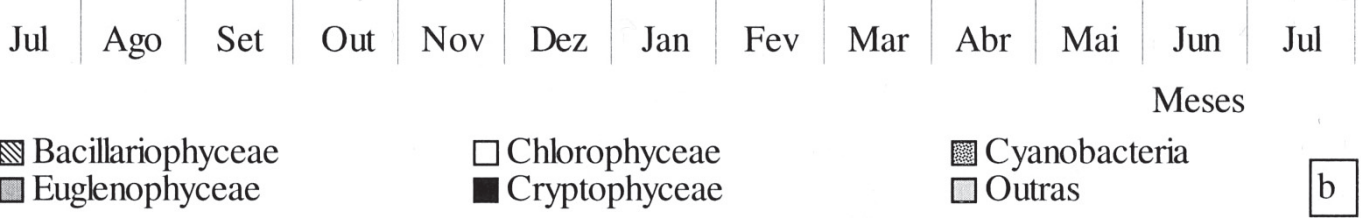

Figura 5. Densidade Relativa (\%) do fitoplâncton no Rio Paranapanema (a) e na Lagoa do Camargo (b), entre julho de 2004 e julho de 2005.

Figure 5. Relative phytoplankton in the Paranapanema River (a) and Camargo Lake (b) from July 2004 to July 2005. 
Elevada variação de biomassa das cinco principais classes fitoplanctônicas foi registrada na Lagoa do Camargo ao longo do estudo (figura 6b). As criptoficeas contribuíram com mais de $54 \%$ da biomassa na estação 2 no período de enchente. As cianobactérias apresentaram elevada contribuição (mais de 53\%) de meados do período de cheia ao início da vazante de 2005, sendo Aphanothece minutissima a espécie predominante. As algas verdes contribuíram mais na estação 1 em dezembro (Botryococcus braunii) e no período de cheia (Eutetramorus fottii e Dictyosphaerium ehrenbergianum). As crisofíceas se destacaram em agosto e fevereiro, devido à elevada biomassa de Dinobryon bavaricum e D. sertularia (figura 6b).

A ordenação das unidades amostrais, através da análise de correspondência canônica (ACC), foi realizada com 13 espécies descritoras selecionadas a partir da densidade e nove variáveis ambientais escolhidas a partir da ACP (maior correlação com os eixos). A correlação de Pearson entre espécieambiente mostrou relação entre as variáveis ambientais e a distribuição das espécies descritoras ao longo do ano de estudo (0,801 para o eixo $1 \mathrm{e}$ 0,749 para o eixo 2). Para avaliar a significância dos primeiros eixos canônicos, foi utilizado o Teste de Monte Carlo, que evidenciou que a ordenação não foi ao acaso $(\mathrm{p}=0,001)$ (figura 7). Os coeficientes canônicos e as correlações intra-set são apresentados na tabela 3.

Ao longo do eixo 1 (15,5\% de explicabilidade) pode-se observar um gradiente espacial que separa as unidades amostrais do Rio (lado positivo do eixo) das unidades amostrais da Lagoa do Camargo (lado negativo do eixo). O eixo 2 (8\% de explicabilidade) evidencia um gradiente temporal com a separação das unidades amostrais de acordo com os hidroperíodos. No rio, Closteriopsis acicularis, Golenkinia radiata e Scenedesmus quadricauda estiveram associadas com as fases de cheia e vazante de 2005, relacionadas a elevadas concentrações de nitrogênio, nitrato e material em suspensão. Enquanto que Dictyosphaerium pulchelum, Aulacoseira granulata e Monoraphidium griffithii estiveram próximos das unidades amostrais da vazante de 2005 , associados a elevados valores de alcalinidade. Entre as unidades amostrais da Lagoa alocaram-se Cryptomonas brasiliensis, associada a altas concentrações de ortofosfato, Discotella stelligera, Cyclotella meneghiniana, Monoraphidium minimum e Mallomonas sp. A maioria delas localizada próxima ao cruzamento dos eixos, indicando correlação com todas as variáveis abióticas (figura 7).

Tabela 3. Coeficientes canônicos e correlações "intra-set" das variáveis ambientais com os eixos 1 e 2 da ACC, realizada com treze variáveis biológicas (espécies descritoras com base na densidade) $(\mathrm{n}=26)$.

Table 3. Canonical coefficients and intraset correlations of environmental variables with axes 1 and 2 of the CCA for thirteen biological variables (density-related descriptor species) $(n=26)$

\begin{tabular}{lccccc}
\hline \multirow{1}{*}{ Variável } & \multirow{2}{*}{ Abreviações } & \multicolumn{2}{c}{ Coeficiente Canônico } & Coeficientes de Correlação “intra-set" \\
\cline { 3 - 6 } & & Eixo 1 & Eixo 2 & Eixo 1 & Eixo 2 \\
\hline Alcalinidade & Alc & 0,502 & $-0,602$ & 0,504 & $-0,517$ \\
Condutividade & Cond & 0,309 & $-0,335$ & 0,431 & $-0,302$ \\
Material em Suspensão & SST & 1,146 & 0,692 & 0,210 & 0,583 \\
Transparência & Transp. & $-0,359$ & $-0,020$ & 0,075 & $-0,661$ \\
Nitrogênio Total & NT & $-0,071$ & 0,175 & 0,063 & 0,690 \\
Fósforo Total & PT & $-0,748$ & $-1,423$ & $-0,173$ & 0,383 \\
Nível Hidrométrico & Cota & 0,650 & $-0,957$ & $-0,014$ & $-0,469$ \\
Ortofosfato & PO4 & $-0,003$ & 0,332 & $-0,359$ & 0,444 \\
Nitrato & NO3 & 0,514 & 0,216 & 0,702 & 0,171 \\
\hline
\end{tabular}



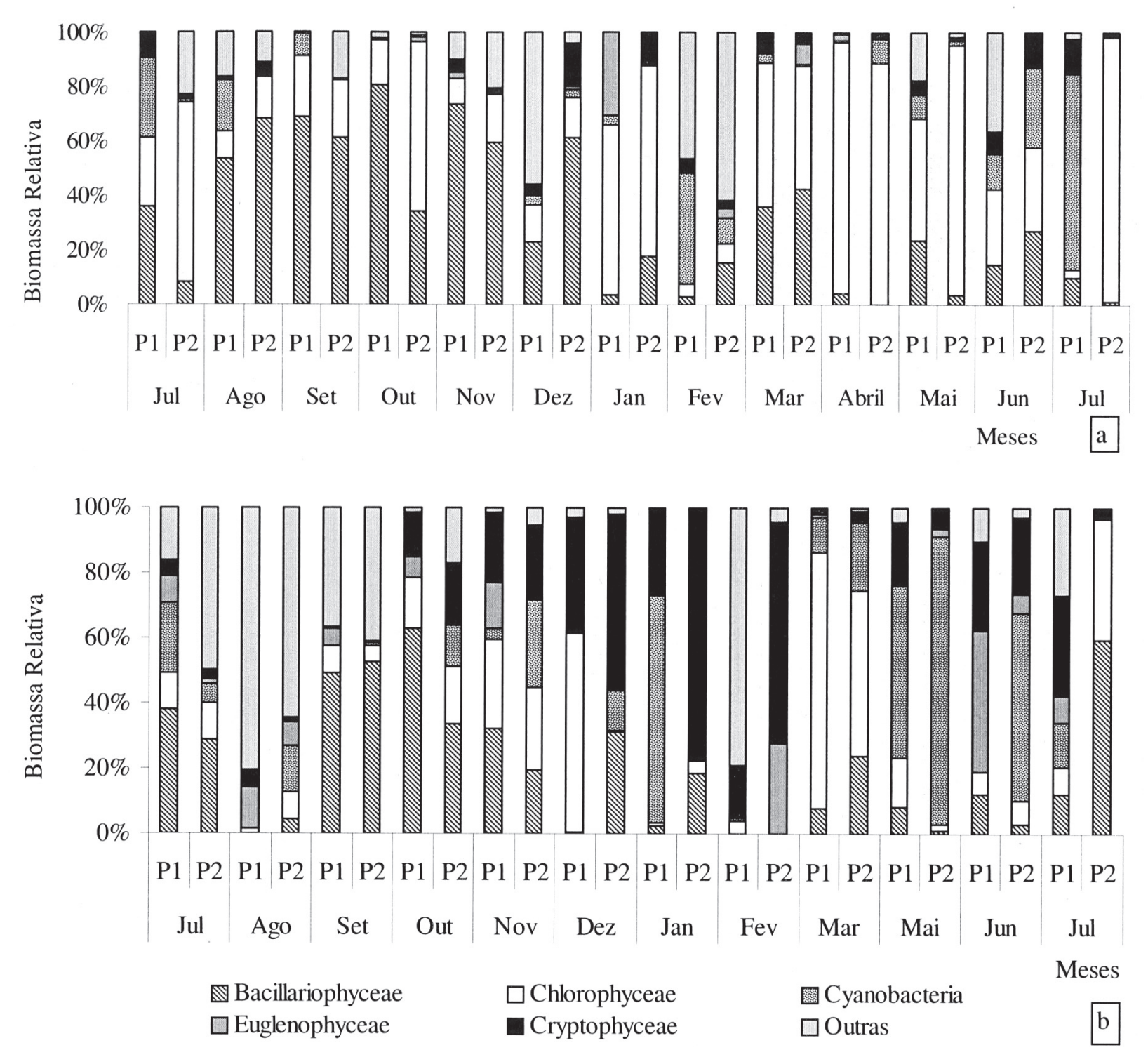

Figura 6. Biomassa relativa (\%) do fitoplâncton no Rio Paranapanema (a) e na Lagoa do Camargo (b), entre julho de 2004 e julho de 2005.

Figure 6. Phytoplankton relative biomass (\%) in the Paranapanema River (a) and Camargo Lake (b) from July 2004 to July 2005. 

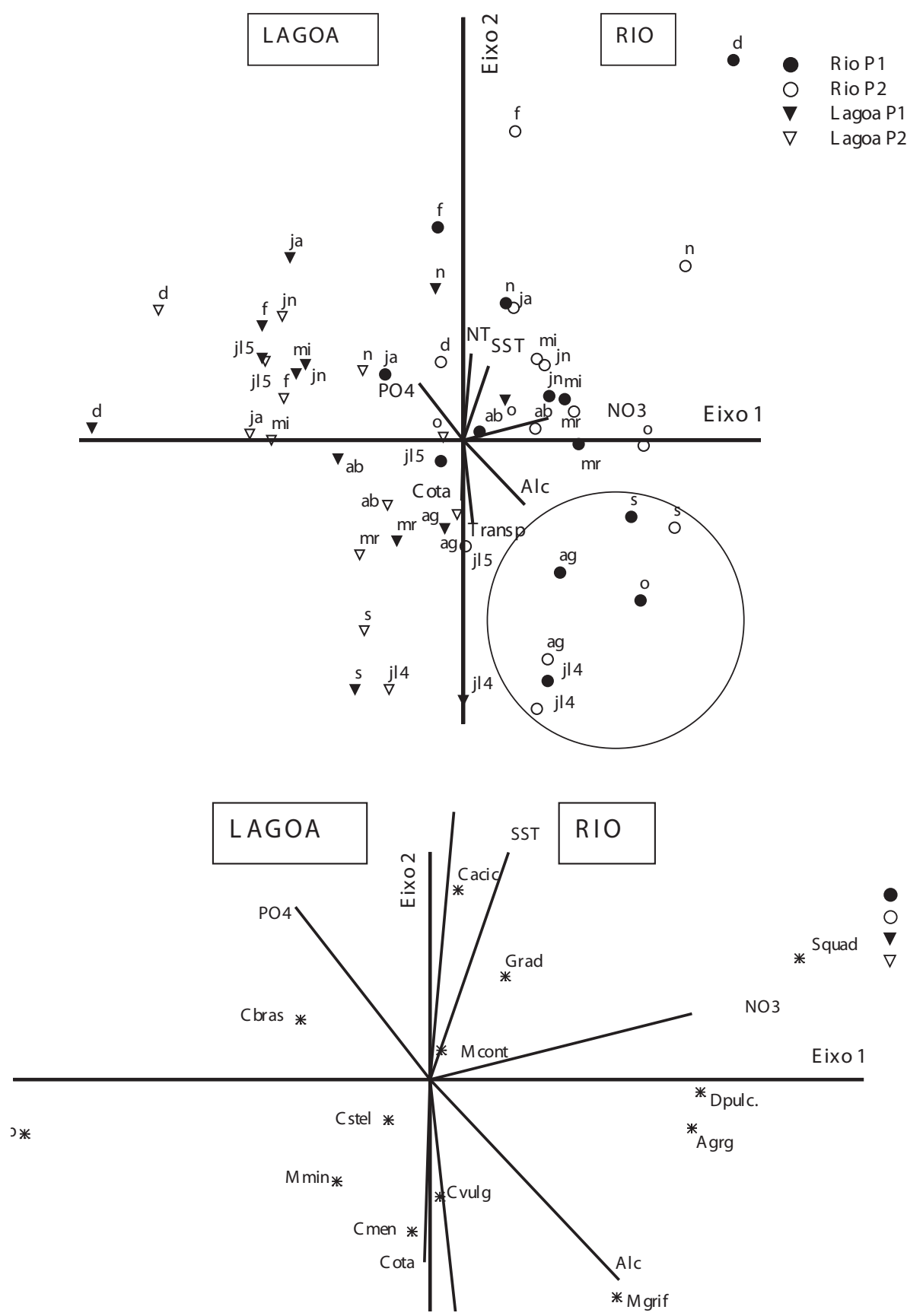

Figura 7. Ordenação pela ACC (eixos 1 e 2) das unidades amostrais em função das variáveis abióticas e biológicas (densidade) no Rio Paranapanema e na Lagoa do Camargo, no período de julho de 2004 e julho de 2005. Para melhor visualização o códigos das unidades amostrais e espécies foram separados: (A) unidades amostrais $(\mathrm{j} 1 / 4=$ julho de 2004 , ag $=$ agosto, $\mathrm{s}=$ setembro, $\mathrm{o}=$ outubro, $\mathrm{n}=$ novembro, $\mathrm{d}=$ dezembro, $\mathrm{ja}=$ janeiro, $\mathrm{f}=$ fevereiro, $\mathrm{mr}=$ março, $\mathrm{ab}=$ abril, $\mathrm{mi}=$ maio, $\mathrm{jn}=$ junho e j15 = julho de 2005) e vetores $($ Transp $=$ transparência, Alc = alcalinidade, $\mathrm{SST}=$ material em suspensão, NT = nitrogênio total); (B) espécies (Agr = Aulacoseira granulta var. granulata, $\mathrm{Cmen}=$ Cyclotella meneghiniana, $\mathrm{Cstel}=$ Discotella stelligera, Cvulg $=$ Chlorella vulgaris, Cacic $=$ Closteriopsis acicularis, Cbras = Cryptomonas brasiliensis, Dpulc $=$ Dictyosphaerium pulchellum, Grad = Golenkinia radiata, Masp = Mallomonas $\mathrm{sp} ., \mathrm{Mcont}=$ Monoraphidium contortum, Mgrf = M. griffthii, Mmin = M. minimum, Squad = Scenedesmus quadricauda).

Figure 7. CCA ordination (axes 1 and 2) of sampling units in relation to the abiotic and biological (density) variables of the Paranapanema River and Camargo Lake from July 2004 to July 2005. For a better analysis, the sampling unit and species are discriminated: (A) sampling units (j1/4: July 2004, ag: August, s: September, o: October, n: November, d: December, ja: January, f: February, mr: March, ab: April, mi: May, jn: June and j15: July 2005), as well as the vectors (Transp. = transparency, Alc = alkalinity, SST = suspended matter, NT = total nitrogen); (B) Species $($ Agr $=$ Aulacoseira granulata var. granulata, Cmen $=$ Cyclotella menghiniana, Cstel = Discotella stelligera, Cvulg $=$ Chlorella vul garis, Cacic $=$ Closteriopsis acicularis, Cbras $=$ Cryptomonas brasiliensis, Dpulc $=$ Dictyosphaerium pulchellum, Grad $=$ Golenkinia radiata, Masp= Mallomonas sp., Mcont = Monoraphidium contortum, Mgrf = M. griffthii, Mmin = M. minimum, Squad = Scenedesmus quadricauda . 


\section{Discussão}

As construções de hidrelétricas nas regiões equatoriais têm modificado o regime de inundação local e afetado as planícies localizadas acima e abaixo das barragens (Junk 1997), as quais representam uma descontinuidade fluvial de origem antrópica, que leva a sérias implicações ecológicas, pois o barramento da água implica em retenção de matéria orgânica, energia e nutrientes (Henry 2003).

A Lagoa do Camargo, normalmente, apresenta-se como um ambiente perene, ligada ao Rio Paranapanema. A condição de conexão permanente está associada ao grande volume de água acumulada no reservatório de Jurumirim, localizado à jusante da região de estudo, que atua como sistema amortecedor dos pulsos hidrológicos de seus tributários alterando freqüência, duração e amplitude dos mesmos (Henry 2005).

Assim, a paisagem não apresenta um padrão típico de áreas alagáveis, cuja característica principal é a oscilação das lagoas entre fase aquática (na cheia), em conexão ao canal do rio, denominada potamofase e fase terrestre (na seca), chamada limnofase, quando estão isoladas (Neiff 1990a, b).

Contudo, ao longo do ciclo sazonal foram observadas flutuações na profundidade da lagoa em consequiência da alimentação lateral de água pelo Rio e as quatro fases comuns nas planícies de inundação (estiagem, enchente, cheia e vazante) puderam ser identificadas através da variação do nível hidrométrico. A Análise de Componentes Principais (ACP) mostrou a tendência de agrupamento temporal dos dados abióticos em função da variação no nível de água. Durante os períodos de enchente e cheia, os pontos relativos ao Rio e a Lagoa apresentaram-se muito próximos no gráfico da $\mathrm{ACP}$, sem possibilidade de distinção e refletiu as características similares para os dois ambientes. No entanto, na vazante e, particularmente, na estiagem eles mostraram-se mais distantes, sendo possível diferenciar os sistemas lótico e lêntico.

No período de estiagem foram encontrados maiores valores de condutividade elétrica da água, alcalinidade, material em suspensão, nitrogênio e fósforo total, nitrito, nitrato e fosfato total dissolvido nos dois ambientes, além de fosfato inorgânico no Rio e silicato reativo na Lagoa. Esses resultados podem ser explicados pela redução no volume de água e seu efeito de concentração nos nutrientes e material suspenso na Lagoa do Camargo e também pela menor velocidade da correnteza, no caso do Rio. Esta fase também foi marcada por baixas transparências, em função do material particulado concentrado no menor volume de água na Lagoa. Nas épocas de enchente e cheia, em função da diluição causada pelo aumento do nível hidrométrico do Rio foi registrado menor valor de condutividade elétrica, alcalinidade, $\mathrm{pH}$, fósforo total e fosfato inorgânico, nitrito, amônia no Rio e fosfato total dissolvido e nitrato no ambiente lacustre. Também são característicos desta época os mais altos valores de temperatura na superfície dos corpos de água no ano, além de altos teores de amônia e de silicato reativo no Rio, em função da lixiviação da bacia hidrográfica no período de chuvas .

A composição de espécies fitoplanctônicas apresentou predomínio de Chlorophyceae, com $41 \%$ da riqueza total, assim como registrado em outras planícies de inundação da América do Sul (Garcia-DeEmiliani 1993, 1997, Train \& Rodrigues 1998, Melo \& Huszar 2000, Oliveira \& Calheiros 2000, Henry et al.2006, Nabout et al.2006,). As algas verdes também se destacam com grande número de táxons em lagos africanos (Kalff \& Watson 1986), reservatórios de usos múltiplos (Tucci et al. 2004, Rodrigues et al. 2005, Bicudo et al. 2006) e reservatórios urbanos (Sant'Anna et al. 1997, Ferragut et al. 2005, Tucci et al. 2006).

As clorofíceas compõem o grupo mais variado de algas e são encontradas em todos os corpos de água continentais. A elevada disseminação das algas desta classe deriva de várias fontes de inóculos, inclusive o ar. Além disso, a colonização, particularmente, das pequenas Chlorococcales é extremamente rápida, devido à elevada razão superfície/volume que resulta em eficiente absorção de nutrientes (Happey-Wood 1988).

Mais alta riqueza e diversidade de espécies foram encontradas no Rio Paranapanema em relação à Lagoa do Camargo. Na mesma região de estudo, Henry (2003) e Henry et al. (2006) relacionaram o elevado número de organismos no Rio à variabilidade da correnteza, a qual poderia atuar como fator de perturbação, resultando em elevados valores de riqueza em comparação a Lagoa do Camargo, ambiente com maior estabilidade hidrológica. Elevadas riqueza, diversidade e uniformidade do zooplâncton no Rio Paranapanema foram associadas ao carreamento de material biológico provindo de local à montante, como de lagoas laterais, tributários e planícies alagáveis. No entanto, Huszar (1994) e Garcia-de-Emiliani (1997) encontraram mais espécies de algas planctônicas nos ambientes marginais do que nos ecossistemas de águas correntes. Esses dados vêm somar às evidências de que 
a zona de transição Rio Paranapanema - Reservatório de Jurumirm não funciona como uma verdadeira planície de inundação, em função da regulação da barragem, visto que é uma área de redução acentuada da velocidade da água (Henry 2006).

Em relação à variação sazonal na estrutura e dinâmica do fitoplâncton, a constatação de que o pulso hidrológico é a principal função de força a atuar nos ambientes alagáveis tem sido enfatizada por muitos autores que estudam essas regiões (Manavella \& Garciade-Emiliani 1995, Garcia-de-Emiliani 1997, Huszar \& Reynolds 1997, Train \& Rodrigues 1998, Melo \& Huszar 2000, Oliveira \& Calheiros 2000, Domitrovic 2003, Taniguchi et al. 2005, Nabout et al. 2006,).

Neste estudo, elevados valores de riqueza e diversidade de espécies foram encontrados no período de estiagem para ambos ambientes, assim como nos dados descritos em Descy (1993), Garcia-de-Emiliani (1997), Ibanez (1998), Taniguchi et al. (2005) e Nabout et al. (2006), possivelmente, associada ao menor regime de distúrbios e, conseqüentemente à maior estabilidade dos ambientes nesse período. Tal característica resulta em competição entre as espécies e desenvolvimento de vários grupos de algas em detrimento das exclusivamente oportunistas (Taniguchi et al. 2005).

Nos dois ambientes, valores mais elevados de densidade e biomassa (biovolume) foram registrados na fase de cheia e as mais baixas na vazante e enchente. Em muitos estudos (Domitrovic 2003, Garcia-de-Emiliani 1997, Huszar \& Reynolds 1997, Nabout et al. 2006, Train \& Rodrigues 1998), as menores densidades e biomassas fitoplanctônicas foram registradas na época de cheia e relacionadas ao efeito de diluição causado pela inundação. Entretanto, os valores mais elevados foram observados durante a estiagem, período em que, normalmente, as lagoas encontraram-se isoladas do canal principal do rio.

Taniguchi et al. (2005) e Peres \& Senna (2000) registraram elevadas biomassas fitoplanctônicas em lagoas marginais na planície do Rio Mogi-Guaçu na época de enchente e cheia e relacionaram o crescimento da população ao aporte de matéria orgânica oriunda da planície. Neste estudo, a enchente provocou redução na densidade e biomassa, assim como na riqueza e diversidade, devido à perturbação ocasionada no ambiente e ao efeito de diluição e de perda de organismos por arrasto da correnteza. Neste período, em termos de densidade, as Cryptophyceae foram predominantes em ambos os ambientes e Cryptomonas brasiliensis apresentou elevados valores na fase de cheia na Lagoa do Camargo. Trata-se de uma espécie oportunista (r-estrategista/C-estrategistas - sensu Reynolds 1988), assim como outras da classe, cujos picos de desenvolvimento são observados após perturbações, quando há declínio de outras populações (Klaveness 1988). Henry et al. (2006) registrou elevada abundância de Cryptophyceae (predomínio de Cryptomonas brasiliensis) durante um período de desconexão prolongada da Lagoa do Camargo, sobretudo em fevereiro, mês mais chuvoso do período.

No presente estudo, após a diluição, a comunidade se restabeleceu com predomínio em densidade, das pequenas Chlorococcales que foram consideradas como espécies oportunistas, registrado também por Garciade-Emiliani (1990). Em relação à biomassa, após a redução na enchente, Chlorophyceae predominou, principalmente no Rio e em um mês na Lagoa, mas as espécies predominantes foram Botryococcus braunii e Eudorina elegans. Inóculos dessa última são bastante comuns no sedimento (Happey Wood 1988) e podem ter sido ressuspensos com a força da correnteza na época de inundação. Esta autora salientou ainda, a relação do gênero Eudorina com a disponibilidade de nitrato, encontrado em elevadas concentrações no Rio Paranapanema no período de cheia. Na Lagoa do Camargo, o aumento de biomassa na fase de cheia foi atribuído a Cyanobacteria Aphanotece minutissima e Chlorococcales, de alto potencial reprodutivo. Nos períodos de vazante e estiagem, as diatomáceas predominaram, principalmente, em termos de biomassa, com destaque para a ordem Centrales (Aulacoseira granulata no rio e Discotella stelligera e D. meneghiniana na lagoa). Apesar da velocidade do vento não ter sido mensurada, sabe-se que os meses de agosto e setembro (vazante) são marcados por fortes ventos que podem ter contribuído para a ressuspensão dessas algas, que necessitam dos movimentos das massas de água para manterem-se na zona eufótica.

Huszar \& Reynolds (1997) no Lago Batata (Pará, Brasil), na planície de inundação amazônica observaram altos valores de biomassa no período de águas baixas, com predomínio, principalmente, de Cryptomonas marsonii Skuja (Cryptophyceae) e Discotella stelligera (Cleve \& Grunow) Houk \& Klee, Aulacoseira granulata (Ehrenbergianum) Simonsem (Bacillariophyceae) e por algumas desmídias. Os autores comentaram que o lento enchimento do lago propiciou o desenvolvimento de um plâncton bastante diversificado, composto por pequenas clorofíceas, diatomáceas e desmídias. No período de cheia, a diluição resultou em baixa abundancia e novamente 
foi verificado predomínio de Cryptomonas spp. e Cyclotella spp. Nabout et al. (2006) evidenciaram as elevadas biomassa do fitoplâncton na estiagem, em que Cryptophyceae foi predominante. Durante a cheia, Aulacoseira spp. representou a comunidade, caracterizada por baixas biomassas. Loverde-Oliveira \& Huszar (2007) na lagoa de inundação Sá Mariana, no Pantanal do Mato Grosso observaram que a época de enchente, cheia e vazante foram marcadas por baixos valores de biomassa, dominada por Aulacoseira granulata e suas variedades, enquanto que no período de seca ocorreram maiores biomassas, em que Aulacoseira spp. se destacou, seguidas por espécies de Botryococcus sp. e Eutetramorus sp.

Garcia-de-Emiliani (1993) em estudo sobre a sucessão sazonal do fitoplâncton no lago El Tigre (Argentina) observou a substituição das pequenas algas com alta razão $\mathrm{S} / \mathrm{V}$ e altas taxas de crescimento por espécies maiores com baixa razão $\mathrm{S} / \mathrm{V}$ e crescimento lento no final da fase de inundação, quando a dinâmica do lago estava mais estável e a carga de nutrientes mais elevada. Em 1997, a autora constatou que os lagos estudados na planície de inundação do rio Paraná apresentaram durante o período em que estavam isolados um padrão sucessional similar ao de lagos temperados, sendo afetados por um distúrbio (fluxo lateral das águas do Rio) que causou reversão ou iniciou nova sucessão fitoplanctônica.

Em Campina do Monte Alegre (SP), Henry et al. (1999) observaram a existência de múltiplos picos de descargas de água do Rio Paranapanema $(60 \mathrm{Km}$ a montante do local de estudo) em cada um dos dois anos de estudo (1992 e 1993). A variabilidade na vazão é forte indício de que antes da construção do Reservatório de Jurumirim, a Lagoa do Camargo, provavelmente, apresentava conexão temporária com o Rio e a região funcionava como uma típica planície de inundação (Henry 2005). Podemos inferir que sem a interferência antrópica, caracterizada pela implantação da barragem de Jurumirim, possivelmente, a comunidade fitoplanctônica teria mais tempo para se auto-organizar durante a limnofase desencadeando sucessão verdadeira na Lagoa do Camargo. A inundação então, funcionaria como um distúrbio intermediário elevando as diversidades após a estabilização, na cheia (Connell 1978). Na dinâmica atual, através da constatação dos resultados obtidos é provável que a inundação ocasione apenas um distúrbio de baixa frequiência, sem resultar em diversidade máxima, devido a constante entrada de água ao longo do ciclo sazonal.

\section{Agradecimentos}

Os autores agradecem a Fundação de Amparo a Pesquisa do Estado de São Paulo-FAPESP (Processo $\left.n^{\circ} 03 / 12473-9\right)$ pela bolsa de estudos concedida a D.C. Granado e, a Hamilton A. Rodrigues e Lúcio Miguel de Oliveira pelo auxílio em campo.

\section{Literatura Citada}

American Public Health Association. 1995. Standart methods for the examination of water and wastewater. 19 ed. Byrd Prepess Spingfield, Washington.

Bicudo, D.C., Ferragut, C., Crossetti, L.O. \& Bicudo, C.E.M. 2006. Efeitos do represamento sobre a estrutura da comunidade fitoplanctônica do Reservatório de Rosana, Baixo Rio Paranapanema, Estado de São Paulo. In: M.G. Nogueira, A. Jorcin \& R. Henry (eds.). Ecologia de reservatórios: impactos potenciais, ações de manejo e sistemas em cascata. 2 ed. Rima, São Carlos, pp. 349-377..

Carlson, R.E. 1977. A trophic state index for lakes. Limnology and Oceanography 22: 361-380.

Connell, J. 1978. Diversity in tropical rain forest and coral reefs. Science 199: 1304-1310.

Descy, J.P. 1993. Ecology of the phytoplankton of the river Moselle: effects of disturbances on community structure and diversity. Hydrobiologia 249: 111-116.

Domitrovic, Y.Z. 2003. Effect of fluctuation in water level of phytoplankton development in three lakes of the Paraná River floodplain (Argentina). Hydrobiologia 510: 175-193.

Ferragut, C., Lopes, M.R.M., Bicudo, D.C. Bicudo, C.E.M. \& Vercelino, I.S. 2005. Ficoflora perifítica e planctônica (exceto Bacillariophyceae) de um reservatório oligotrófico raso (lago do IAG, São Paulo). Hoehnea 32: 137-184.

Garcia-de-Emiliani, M.O. 1990. Phytoplankton ecology of the middle Paraná River. Acta Limnologica Brasiliensia 3: 391-417.

Garcia-de-Emiliani, M.O. 1993. Seasonal sucession of phytoplankton in a lake of the Paraná River floodplain, Argentina. Hydrobiologia 264: 101-114.

Garcia-de-Emiliani, M.O. 1997. Effects of water level fluctuations on phytoplankton in a river-floodplain lake system (Paraná River, Argentina). Hydrobiologia 357: 1-15.

Golterman, H.L., Clymo, R.S. \& Ohnstad, M.A.M. 1978. Methods for physical and chemical analysis of freshwater. 2 ed. Blackwel Scientific, Oxford.

Happey-Wood, C.M. 1988. Ecology of freshwater planktonic green algae. In: C.D. Sandgren (ed.). Growth and reproductive strategies of freshwater phytoplankton. Cambridge University Press, Cambridge, pp.175-226. 
Henry, R. 2003. Ecótonos nas interfaces dos ecossistemas aquáticos. Rima, São Carlos.

Henry, R. 2005. The connectivity of the Paranapanema River with two lateral lakes in its mouth zone into the Jurumirim Reservoir. Acta Limnologica Brasiliensia 17: 57-69.

Henry, R., Santos, A.A.N. \& Camargo, Y. R. 1999. Transporte de sólidos suspensos, $\mathrm{N}$ e P total pelos Rios Paranapanema e Taquari e uma avaliação de sua exportação na Represa de Jurumirim (São Paulo, Brasil). In: R. Henry (ed.). Ecologia de reservatórios: estrutura, função e aspectos sociais. FAPESP/FUNDIBIO, Botucatu pp. 689-710.

Henry, R., Ushinohama, E. \& Ferreira, R.M.R. 2006. Fitoplâncton em três lagoas marginais ao Rio Paranapanema em sua desembocadura no Reservatório de Jurumirim (São Paulo, Brasil) durante um período prolongado de seca. Revista Brasileira de Botânica 29: 399-414.

Hillebrand, H., Dürselen, C.D., Kirschiel, D., Pollingher, U. \& Zohary, T. 1999. Biovolume calculation for pelagic and benthic microalgae. Journal of Phycology 35: 403-424.

Huszar, V.L. 1994. Fitoplâncton de um lago amazônico impactado por rejeito de bauxita (Lago Batata, Pará, Brasil): estrutura da comunidade, flutuações espaciais e temporais. Tese de Doutorado, Universidade Federal de São Carlos, São Carlos

Huszar, V.L.M. \& Reynolds, C.S. 1997. Phytoplankton periodicity and sequences of dominance in an Amazonian floodplain lake (Lago Batata, Pará, Brazil): responses to gradual environmental change. Hydrobiologia 346: 169-181.

Ibañez, M.S.R. 1998. Phytoplankton composition and abundance of a central Amazonian floodplain lake. Hydrobiologia 362: 79-83.

Junk, W. J. 1980. Áreas inundáveis - Um desafio para a Limnologia. Acta Amazonica 10: 775-795.

Junk, W.J. 1997. The Central Amazon Floodplain: Ecology of a Pulsing System. Springer-Verlag. Berlin.

Kalff, J. \& Watson, S. 1986. Phytoplankton and its dynamics in two tropical lakes: a tropical and temperate zone comparison. Hydrobiologia 138: 161-176.

Klaveness, D. 1988. Ecology of the Cryptomonadida: a first review. In: C.D. Sandgren (ed.). Growth and reproductive strategies of freshwater phytoplankton. Cambridge University Press, Cambridge, pp. 105-133.

Koroleff, F. 1976. Determinations of nutrients. In: K. Grashoff (ed.). Methods of sea water analysis. Verlag Chemie, Weinhein, pp. 177-181.

Loverde-Oliveira, S.M. \& Huszar, V.L.M. 2007. Phytoplankton ecological responses to the flood pulse in a Pantanal lake, Central Brazil. Acta Limnologica Brasiliensia 19: 117-130.
McCune, B. \& Mefford, J.J. 1997. PC-ord. Multivariate analysis of ecological data, version 3.0. Oregon MjM Software Design, Gleneden Beach.

Mackeret, F.I.H., Heron, J. \& Talling, J.F. 1978. Water analysis: some revised methods for limnologists. Freshwater Biological Association, London.

Manavella, M.I.A. \& Garcia-de-Emiliani, M.O. 1995. Composicion y dinamica del fitoplancton en una seccion transversal del Rio Correntoso (llanura aluvial del Rio Parana). Revista de la Asociación de Ciencias Naturales del Litoral 26: 39-54.

Melo, S. \& Huszar, V.L. 2000. Phytoplankton in an Amazonian flood-plain lake (Lagoa Batata, Brasil): diel variation and species strategies. Journal of Plankton Research 22: 63-76.

Neiff, J.J. 1990a. Ideas para la interpretación ecológica del Paraná. Interciencia 15: 424-441.

Neiff, J.J. 1990b. Aspects of Primary Productivity in the lower Parana and Paraguay riverine system. Acta Limnologica Brasiliensia 3: 77-113.

Nabout, J.C., Nogueira, I.S. \& Oliveira, L.G. 2006. Phytoplankton community of floodplain lakes of the Araguaia River, Brazil, in the rain and dry seasons. Journal of Plankton Research 28: 181-193.

Oliveira,M.D.\& Calheiros,D.F.2000. Flood pulse influence on phytoplankton communities of the south Pantanal floodplain, Brazil. Hydrobiologia 427: 101-112.

Paidere, J., Gruberts, D. \& Skute, A. 2007. Impact of two different flood pulses on planktonic communities of the largest floodplain lakes of the Daugava River (Latvia). Hydrobiologia 592: 303-314.

Peres, A.C. \& Senna, P.A.C. 2000. Estudo quantitativo e estatístico do fitoplâncton da Lagoa do Diogo em um ciclo hidrológico. In: J.E. Santos \& J.S.R. Pires (eds.). Estação Ecológica de Jataí. Rima, São Carlos, pp. 482-495.

Pompêo, M.L.M., Henry, R. \& Moschini-Carlos, V. 1999. Ecologia de Echinochloa polystachya do Rio Paranapanema - SP, Brasil. In: R. Henry (ed.). Ecologia de reservatórios: estrutura, função e aspectos sociais. FAPESP/FUNDIBIO, Botucatu, pp. 737-767.

Putz, R. \& Junk, W.J. 1997. Phytoplankton and periphyton. In: W.J. Junk (ed.). The Central Amazon Floodplain: Ecology of a pulsing system. SpringerVerlag, Berlin, pp. 207-222.

Reynolds, C.S. 1988. The concept of ecological succession applied to seasonal periodicity of freshwater phytoplankton. Mitteilungen/Internationale Vereinigung fur Theoretische und Angewandte Limnologie 23: 683-691.

Rodrigues, L.C., Train, S., Pivato, B.M., Bovo, V.M., Borges, P.A.F. \& Jati, S. 2005. Assembléias fitoplanctônicas de trinta reservatórios do Estado do Paraná.In: L. Rodrigues, S.M. Thomaz, A.A. Agostinho \& L.C. Gomes (orgs.). Biocenoses em reservatórios: 
padrões espaciais e temporais. Rima, São Carlos, pp.57-85.

Sant’Anna, C.L., Sormus, L., Tucci, A. \& Azevedo, M.T.P. 1997. Variação sazonal do fitoplâncton do Lago das Garças, São Paulo, SP. Hoehnea 24: 67-86.

Shannon,C.E.\& Weaver,W. 1963. A mathematical theory of comunication. University of Illinois Press, Urbana.

Shepherd, G.J. 1996. Fitopac 1: manual de usuário. Departamento de Botânica, Universidade Estadual de Campinas, Campinas.

Sommer,U.,Padisák,J., Reynolds, C.S.\& Juhász-Nagy,P. 1993. Hutchinsosn's heritage: the diversity-disturbance relationship in phytoplankton. Hydrobiologia 249: 1-7.

Strickland, J.D.H. \& Parsons, T.R. 1960. A manual of seawater analysis. Fisheries Research Board of Canada Bulletin 125: 1-185.

Taniguchi, G.M., Bicudo, D.C. \& Senna, P.A.C. 2005. Gradiente litorâneo-limnético do fitoplâncton e ficoperifíton em uma lagoa da planície de inundação do Rio MogiGuaçu. Revista Brasileira de Botânica 28: 137-147.

Teixeira, C.\& Kutner, M.B. 1962. Plankton studies in a mangrove environment. I - First assessment of standing stock and ecological factors. Boletim do Instituto Oceanográfico 12: 101-124.

Toledo Junior, A.P., Talarico, M., Chinez, S.J. \& Agudo, E.G. 1983. A aplicação de modelos simplificados para a avaliação de processo de eutrofização em lagos e reservatórios tropicais. In: Anais do $12^{\circ}$ Congresso de Engenharia Sanitária e Ambiental, Balneário Camboriú, pp. 1-34.

Train, S. \& Rodrigues, L.C. 1998. Temporal flutuations of the phytoplankton community of the Baía River, in the upper Paraná River floodplain, Mato Grosso do Sul, Brazil. Hydrobiogia 361: 125-134.

Tucci, A., Deberdt, J. \& Deberdt, G.L.B. 2004. Análise da comunidade fitoplanctônica do reservatório de Salto Grande (Americana, SP): uma revisão dos estudos desenvolvidos em sistemas eutróficos. In: E.L.G. Espíndola, M.A. Leite \& C.B. Dornfeld (orgs.). Reservatório de Salto Grande (Americana, SP): caracterização, impactos e propostas de manejo. Rima, São Carlos, pp. 107-153.

Tucci, A., Sant'Anna, C.L., Gentil, R.C. \& Azevedo, M.T.P. 2006. Fitoplâncton do Lago das Garças, São Paulo, Brasil: um reservatório urbano eutrófico. Hoehnea 33: 147-175.

Utermöhl, H. 1958. Zur Vervollkommung der quantitativen Phytoplankton-Methodic. Mitteilung Internationale Vereinigung Theoretische und Angewandte Limnologie 9: 1-38.

Wetzel, R.G. \& Likens, G.E. 1991. Limnological analysis. 2 ed. Springer-Verlag, New York. 